\title{
Perceptions of Academics and Students as Customers: A survey of administrative staff in higher education
}

\section{Tim Pitman}

To cite this article: Tim Pitman (2000) Perceptions of Academics and Students as Customers: A survey of administrative staff in higher education, Journal of Higher Education Policy and Management, 22:2, 165-175, DOI: 10.1080/713678138

To link to this article: https://doi.org/10.1080/713678138

冊 Published online: 03 Aug 2010.

6 Submit your article to this journal

Џll Article views: 925

Q View related articles ¿

4 Citing articles: 65 View citing articles 


\section{Perceptions of Academics and Students as Customers: a survey of administrative staff in higher education}

TIM PITMAN, Curtin University of Technology, Australia

ABSTRACT This article examines the extent to which university administrative staff perceive academics and students as customers. These perceptions have an effect on the provision of quality customer service. The role of administrative staff in the educational experience for students has been generally ignored in academic research. A discussion of quality service provision in higher education can be enhanced by a consideration of the perceptions held by administrative staff of academics and students as customers. Administrative staff perceptions were analysed by surveying staff from Curtin University's Academic Registrar's Office (ARO). Findings of this survey indicate that administrative staff have ambivalent feelings towards academics as customers and highlight interpersonal skills between the two groups as a major challenge in facilitating quality customer service. In dealing with students, administrative staff move beyond the processes of mere service-providers and incorporate a mentor role into their processes. Administrative staff tend to relate closely to students, perceiving them as internal customers.

\section{Introduction}

Management practices in Australian universities are under constant review, given the current need for economic accountability and the increased focus on consumer choice. Consequently, there have been various attempts to recognise the interaction between these groups and better manage the way in which services are provided (for example, Brennan \& Bennington, 1998; Banata \& Kuh, 1998). One of the anticipated outcomes of these reviews is an improvement in customer service in universities.

There is a possibility, however, that too structured a relationship between administrative staff and academics, and administrative staff and students, may have detrimental effects. For instance, service in non-university environments can often be superficial, based on immediate, one-off transactions. By contrast, administrative staff, academics and students tend to deal on a more intimate and long-term basis. In addition, internal customers (such as academics) may not appreciate being treated as a 'customer', that is, someone who has no relationship with the administrative staff member beyond the immediate transaction.

In a study of administrative staff working in the Academic Registrar's Office (ARO) 
of Curtin University of Technology, Western Australia, issues of quality service were examined. An analysis of these results sheds further light on the ways in which the provision of quality service in universities can be affected by the perceptions that administrative staff members have of academics and students.

\section{Background Literature}

In recent times, much has been written about quality education in higher education institutions. According to Marceau (1995, p. 113), this has been largely due to the increased economic accountability of these institutions, as a result of reduced government funding and a larger social focus on consumer choice. Economically rationalistic policies by successive Commonwealth governments have necessitated a push, by universities, to make courses more what consumers want, rather than what universities believe should be taught. These new ways of looking at 'customers' of education have created a need to review the relationship between these consumers and university employees.

Most of what has been recently written about quality service focuses on the teaching aspect of education. Many commentators have called for universities to review their teaching standards (for example, Edmond, 1995; Reid, 1996; Brennan \& Bennington?, 1998). As Edmond (1995, p. 52) argues:

Quality is the focus of the moment in higher education in Australia... ensuring that institutions maintain a high level of attention to quality issues in order to gain access to funds and achieve a 'grading' that, however discounted by the reviewers, cannot help but be the focus of interest within and without Australia.

The administrative side of higher education, however, has been largely overlooked when the issue of quality service has been considered. This is not surprising, for two reasons. Firstly, universities, naturally, remain focussed on teaching and research, with the administration tasks existing to facilitate these aims. Secondly, most of what has been written is done so by academics, who focus on the areas that concern them the most. This has meant, however, that the role of administrative staff in tertiary organisational culture has been somewhat ignored. Banata and Kuh (1998, p. 41) have drawn attention to this oversight and state:

A faculty cannot by itself accomplish the [university's] objectives for a student's intellectual and personal development; it needs the cooperation of others who work with students where students spend the majority of their time.

In higher education administration, customer service moves beyond mere 'service transactions' and takes on a wider focus. Bean and Bradley (1986, p. 399-400) refer to what they call the 'institutional fit', that is, the extent which a student feels that she or he belongs at the institution. This translates, in general terms, into what they refer to as 'satisfaction'. Interestingly, their survey found that 'satisfaction had a greater influence on [academic] performance than performance had on satisfaction'. To treat the student as a customer requires a perception of quality of service not just on academic or teaching criteria, but also on the extent to which the student enjoys campus life. Student services, including administration, have an important role to play in this respect.

When discussing quality service, language becomes very important. How the consumer of the service is defined partly determines the view the university takes of the consumer and thus the service they provide to them. Understanding trends in the management of universities requires understanding the impact of the language of management, as Marceau (1995, p. 113) and Reid (1996, p. iii) have observed. The way in which service 
providers perceive both their role and relationship to the consumer will affect their behaviour. The use of language is closely linked with the perception this creates of customers and thus the way in which they are treated. For instance, Sirvanci (1996, p. 101) notes that, unlike a 'conventional' customer, the university student does not usually have full freedom of choice with the product (knowledge/education), responsibility for paying the price and might not even 'qualify' to purchase the product. It is unlikely, therefore, that the service provider will consider themselves in a typical customer-employee relationship.

Definitions of internal and external customers become problematic in a university setting. A private sector view of this dichotomy would place all staff members (academic and administrative) as internal customers and the remainder (including students) as external, as does Dervitsiotis (1995). However there is some dispute in the literature relating to this. Sirvanci (1996, p. 100) views the student as an internal customer, taking part in the production of knowledge, with the future employers the true external customer. This correlates with Marceau's (1995, p. 113) belief that universities have changed from institutions of social leadership to organisations that merely meet consumer demand. What sort of customer the administrative staff perceive themselves to be serving (that is, internal or external) can affect the style and level of service they provide.

Several commentators have noted the relationship between academic and administrative staff as being an area of potential conflict (for example, Reid 1998; Bladerston 1995 , p. 133). According to Bladerston, academic staff create a value system in which administrative staff-even those at professional and senior levels - cannot share directly. Worse yet, administrative staff are sometimes the victims of academic snobbery and academic contempt for bureaucracy. In reaction, many administrative staff retreat into bureaucratic rigidity as a defence. Reid (1998), however, suggests that there may be a potential positive in this conflict, with the winner being the student. He argues that there is evidence to suggest that academics often challenge bureaucracy to ensure that students are not disadvantaged by unnecessary red tape.

Curtin University of Technology has also considered the issue of customers, and customer service, from a tertiary administration point of view. A notable example has been the joint venture between the ARO and the Student Guild, resulting in the Student Charter. Unlike most private sector charters - which are little more than a guarantee of minimum service standards - the Student Charter is a two-way agreement between the University and students, that clearly spells out the expectations that each group has upon the other. For instance, the Charter promises that students will be given an environment conducive to study, free of prejudice or bias. At the same time, however, it points out that the students have a part to play in creating this environment themselves and requires them to behave tolerantly at all times to other individuals or groups. Another example is the promise of grounds for appeal against unfair assessment but the requirement of students to be aware of and obey the deadlines and standards associated with submission of assignments, before they can appeal. This is one of the few examples of quality service provision that firstly acknowledges the part that the tertiary customer (such as the student) plays in the process and secondly, has actively sought feedback from a primary customer group (the students) via the Student Guild.

\section{Methodology}

The key concept in this research was the perception that administrative staff have of academics and students as customers - a concept that is difficult to quantify. Conse- 
quently, a phenomenological approach was taken to this research. The study involved interviewing thirteen staff from the Curtin University's Academic Registrar's Office (ARO), including the Senior Executive of the Office of University Administration (under whose direction the ARO falls). The ARO defines University policy and performs the central administrative functions for the entire organisation. Of the thirteen staff interviewed, two were classed as senior management, three were middle or line management and the remaining eight were general/administrative staff.

Staff were asked about their perceptions of academics and students as customers and how they saw their role, as service providers, to them. The interviews were semi-structured and concentrated on the personal perceptions of the interviewee. Although the interviews were semi-structured, the same questions were initially asked of all staff, so as to provide a focus for their thoughts and to ensure that the same issues were discussed with all staff.

\section{Analysis of Results}

\section{Secondary data}

At the same time as this study, although independent to it, the ARO sent a questionnaire to all staff, asking them to identify their customers. The results of the survey are shown in Table 1.

TABLE 1. Results from the Academic Registrars Office Questionnaire

\begin{tabular}{|c|c|c|}
\hline & As a number & As a percentage \\
\hline Number of questionnaires: & 42 & $\mathrm{~N} / \mathrm{A}$ \\
\hline Number of responses: & 28 & $66.67 \%$ \\
\hline $\begin{array}{l}\text { Number of respondents who defined staff and students } \\
\text { as either the only, or primary customers (including } \\
\text { prospective students): }\end{array}$ & 19 & $67.8 \%$ \\
\hline $\begin{array}{l}\text { Number or respondents who defined anyone who } \\
\text { contacted them, as part of their work, as a customer: }\end{array}$ & 8 & $28.6 \%$ \\
\hline Miscellaneous responses: & 1 & $3.6 \%$ \\
\hline
\end{tabular}

The above responses show that over two-thirds of ARO staff see themselves, primarily, as service providers to students (or intending students) and other staff.

TABLE 2. Demographics of participants in the study conducted in the Academic Registrar's Office

\begin{tabular}{lll}
\hline & As a number & As a percentage \\
\hline Number of interviewees: & 13 & \\
Male/Female ratio: & $7-6$ & $53.8 \%-46.2 \%$ \\
Management General staff ration & $5-8$ & $38.5 \%-61.5 \%$ \\
$\begin{array}{l}\text { Average time working in higher education: } \\
\text { Average time working in ARO: }\end{array}$ & 5.9 years & N/A \\
$\begin{array}{l}\text { Average time working in other (non-higher eduction): } \\
\text { Number of staff who had moved from academia into }\end{array}$ & 8.4 years & N/A \\
$\begin{array}{l}\text { administration: } \\
\text { Number of staff who were/had been a higher education }\end{array}$ & 0 & $0 \%$ \\
student: & 10 & $76.9 \%$ \\
\hline
\end{tabular}




\section{Goals of the Academic Registrar's Office (ARO)}

Of the thirteen interviewees, nine explicitly referred to the provision of quality customer service to the ARO's customers as being a key - or prime-goal of the ARO. The remaining four implicitly referred to quality service provision, with the use of terms such as 'helping', 'guiding' and 'supporting'. Interestingly, most chose not to define any boundaries, or limitations of this service. For instance, the following qualifiers were given to service provision:

'To provide the best possible service to both staff and students'

'To provide the best possible customer service'

'To provide service to Schools, students and prospective students'

'To provide good service to students'

For the majority of interviewees (nine out of thirteen-see Table 2) quality service provision was open-ended and not based on any form of Management by Objectives (MBO). Thus, they did not view quality in terms of targets, or goals. The concept of quality service for these people was passive, that is, a level of acceptable service was not pre-determined, rather the staff endeavoured to provide quality service wherever possible. Further discussion of this topic revealed that these nine subjects did not feel that it was possible to define quality service in terms of policies, targets or even customer feedback (which will be discussed further below). This is not to say that quality service is neglected, rather that line management and administrative staff are empowered to improve service where they can, but without specific direction.

\section{Perceptions of Quality Service Provision}

Most of the staff interviewed felt that customer satisfaction was not a pre-requisite to customer service. Only three of the respondents highlighted this as a compulsory factor for quality service provision. Two felt that part of quality service provision was the ability to explain to a dissatisfied customer the reasons for a particular decision, but felt that ultimately it was possible that some customers would fail to be satisfied under any circumstances. Part of this 'fatalistic' attitude to customer satisfaction is a result of the particular role that the staff of the ARO play in terms of University policies. All staff invariably encounter a situation where the policies which they administer cause customer dissatisfaction. For instance, those staff who work in the Examinations Office will sometimes have to advise students that a 'Fail' grade cannot be struck from their record. In this instance, the credo 'The customer is always right' becomes harder to live by, or rather it would be more accurate to say, 'which customer?' In administering policies, the interests of one customer group can sometimes take precedence over (and cause dissatisfaction within) another customer group. In the example above, the interests of potential employers of the University's students - who require accurate academic records and course completion details - are more important than the interests of some students, who may wish to cut corners in respect of their education.

Respondents who did define quality service provision within certain parameters, or as an objectively managed concept, concentrated on the University's policies. In these cases, quality service provision was most commonly defined as implementing the University's policies to ensure the smooth running of the institution. Customer satisfaction in this case takes on even lesser importance, as the prime focus for the staff member is ensuring that policies are adhered to, regardless of how they affect staff and students.

The perceptions that staff members held towards the word 'customers', significantly, showed a degree of concern. Of the thirteen interviewed, four respondents associated the 
word with negative connotations and of the remaining nine, a further four felt the word was 'inappropriate'. Almost two-thirds, therefore, had misgivings with the word 'customer'. All thirteen staff declined to use the term 'customer' in day-to-day dealings in the Office. In fact, the use of the word seems to be almost exclusively reserved for correspondence or communication between staff in formal settings, such as meetings or minutes. The negative connotations associated with the word 'customer' concerned its implications that there was a shallow relationship between the administrative staff member and academic, or administrative staff member and student. Staff felt that the word 'customer' suggested that they had no empathy with the person they were serving and also felt that it demeaned their role as service providers. They felt that this was a two-way perception, that is, use of the word 'customer' would be perceived by the academic or student to mean that the administrative staff member placed no value on the relationship between the two parties, and was there to offer only token support.

When asked for alternative words to 'customer' some offered 'client', as they felt this implied a stronger, one-to-one relationship between customer and service provider. However nearly all (eleven out of thirteen) said that ultimately they chose to refer to students as students, and academics as academics. Terms such as 'customer' and 'client' were considered the domain of private (particularly retail) businesses and had no place in the jargon of a higher education establishment.

\section{Perceptions of Students as Customers.}

When asked about their perceptions of students as customers, the responses from administrative staff were positive. Despite their reservations about the word, all staff recognised students as customers. Furthermore, there was an almost unanimous consensus that the customer-service provider relationship was in some way special and unlike one that would exist in a retail environment. Only one of the thirteen respondents felt there was no difference between a student as customer and a customer in the private, retail sense. The remaining twelve identified a greater feeling of empathy with students than 'normal' customers.

Staff felt very strongly that they were in some way associated with the teaching experience for the student, and did not exist merely to support students administratively. This supported the vision of senior administration staff, whose participants in this project identified the role of their staff in the educational process as crucial. Key words by staff in this respect were in perceiving themselves as 'mentors', 'relating to students' and of a partnership between staff and students. This correlated with the University's Student Charter, as previously mentioned.

Although positive about the role that they played for the University, administrative staff were somewhat more matter-of-fact about how they believed students perceived them. Six of the thirteen believed that students had a negative view of them and saw them as being a part of an impersonal, unhelpful bureaucracy. A further five respondents were neutral on the subject, either offering no opinion or feeling that the student did not pay much thought to the role of the administrative staff member. Only two interviewees felt that students perceived them as being a positive influence on their university experience. The senior management respondents identified the role of the administrative staff in the University as one that needed to be promoted more. One wanted official recognition, that is, he wanted the actions of the administrative staff to be part of the decision making process for students. Ideally, part of the student's positive memories and future recommendations of the University would include the quality service provided by 
its administrative arm. Perceptions held by the administrative staff interviewed suggest that, whilst they embrace this philosophy and endeavour to promote it, they feel that their service goes largely unnoticed by the students. As one remarked 'students remember the quality of teaching, not the quality of administration'. Further to this, several respondents noted that the majority of student contact with administration was minimal, when compared to contact with academic staff.

Finally, it was noted that $76.9 \%$ of respondents either were, or had, been higher education students. This accounts for the very definite responses received when staff were asked to give their opinion of how they felt students perceived the administrative staff. On the whole, the respondents felt that they knew very well, as they could empathise with students on the basis that they were, or had been, students themselves. In addition, of the front-line staff interviewed - that is, those nine who had daily dealings with students - seven were in the same age group as the majority of the students (that is, mid-twenties with the average student age being twenty-six). This undoubtedly had a bearing on the empathetic attitude to students. The concern, however, is that management might find it hard to convince administrative staff that they 'make a difference' to the students as many staff still retained negative impressions of administrative functions that they had as students themselves.

\section{Perceptions of Academic Staff as Customers.}

Administrative staff members, overall, were ambivalent about their perception of academics as customers. Although all respondents acknowledged the role they played as service providers to academics, there was a greater deal of variance when they tried to define their precise relationship. All of them agreed that academics were customers, however most respondents qualified the comment in some way. Four respondents classified them as peers and customers, or as one put it: 'like a colleague who you treat as a customer'. Two more respondents admitted to feelings of inferiority when dealing with academic staff members and suggested that while they viewed them as co-workers, they felt that the academics occupied a greater position of power than they did.

A degree of wariness was evident, from administrative staff members' comments, when dealing with academic staff members. Four staff felt that academics were, generally, difficult to deal with. A further five felt that it was a minority of academics who were difficult and that this affected the overall perception that administrative staff had of them. Only one front-line staff member offered no negative perceptions of academics as customers. This was even more strongly highlighted when the respondents discussed the perceptions that they believed academic staff members had of them. Eleven out of thirteen felt academics considered themselves superior to administrative staff and held negative stereotypes about them, such as being unnecessarily bureaucratic.

More than half of the respondents (seven) felt negative stereotypes, concerning academic staff, existed. They believed that these were primarily based on a perception that interpersonal skills were not paramount for academic staff and made them initially difficult to deal with. The senior executive respondent noted that the very skills that set certain academics apart, such as individuality, originality and having a strong personality, made them difficult to deal with from an administrative point of view. Most respondents felt that these were barriers that could be overcome, most usually via developing a personal relationship with the academic concerned. The strength and value of these personal relationships were highlighted in a number of ways. Firstly it was interesting that one respondent made reference to a particular academic with whom she had 
developed a rapport and liked dealing. Another respondent, at another time, named the same academic staff member as difficult and hard to work with. Secondly, two respondents noted that it was common for academic staff members to 'follow them around' as they moved from one role to another. Consequently, academics tended to speak to a specific person when they had to contact the ARO, even if the issue in question was not the responsibility of the administrative officer. Ten out of thirteen respondents said that they felt it was essential to develop a personal working relationship with academic staff.

The general perception, by respondents, was that there were two clear cultures operating with administrative and academic staff. Comments from the respondents that highlighted this included:

'Sometimes they don't have a grip on the reality of University life'

'Academics place little importance in paperwork'

'Many [academics] live in ivory towers'

'[Academics] don't appreciate what we do'

The overwhelming feeling of the respondents was that academic staff had different motives for working in a university from administrative staff members and used a different value system from their own. Although some respondents (two out of thirteen) resented this and felt that the administrative culture was in some way better, the rest preferred to look upon academic staff as merely different, rather than better or worse. The overall feeling was that dealing with this different culture was a challenge, sometimes frustrating, but on the whole acceptable.

The most negative responses came when administrative staff were asked to give their perceptions of what academic staff thought of them. The almost unanimous feeling (twelve out of thirteen) was that academic staff looked down on their administrative counterparts and did not fully value their role in the University. Common responses included:
'[Academics] view us as being lower to them'
'[Academics] view us with contempt'
'[Academics] view us as ... bureaucratic'
'[Academics] think we're inflexible'
'There's a combination of dismissiveness and dislike [from academics]'

These responses suggested an element of resignation, that is, administrative staff felt that they were operating in a situation where they respected their colleagues but that the feeling was not reciprocated. It is interesting that no examples were given to support this perception by a single respondent. Rather, the perceptions seem to be based upon an assumption that a comparison of the role of the administrative officer and the role of the academic, by an impartial party, would somehow result in a devaluing of the former. Administrative staff seemed to believe that academic staff felt superior to them, even though this was not necessarily evidenced by the behaviour displayed by academic staff.

\section{Definition of Internal and External Customers.}

It was interesting to note the responses by staff, when differentiating between internal and external customers. Most private sector definitions would list internal customers as those who were employed by, or worked for the organisation and the rest as external customers. Eight out of thirteen respondents (61.5\%), however, defined students as internal customers. Thus, while administrative staff view students as customers, they 
perceive a much stronger bond with them than would be found in private, retail organisations. Significant evidence of the empathy that the staff have with students was observed, based on almost 85 percent of staff being, or previously being, students themselves. When elaborating on their definition of students as internal customers, respondents again referred to the special customer-service provider bond that existed and of them working together towards a common goal, namely the acquisition of knowledge. It would appear, therefore, that Sirvanci's view (1996, p. 100) of the student as internal customer and the future employer as the true external customer, is one shared by many administrative staff.

\section{Conclusion}

University administrative staff are clearly aware of the different value systems and cultures that exist in today's Australian universities. This affects the perception of their customers in various ways. For example, to someone without experience in higher education institutions, it might be expected the value system of administrative staff and academic staff would be much closer than that of administrative staff and students. This research, however, has found that administrative staff are more likely to find convergence in their value system with that of the students, rather than that of the academics. This categorisation indicates a greater level of association - in the respondents' perceptionwith their primary customer base, than one might expect in a private, retail service organisation.

Administrative staff perceptions of academics as customers seem to be coloured by stereotypes of academics as eccentric individuals with under-developed interpersonal skills. Many administrative staff pre-suppose that such tendencies are pre-requisites for success in academia and consequently are a 'cross' that must be borne by the administrators. These perceptions play a fundamental role in the early stages of interaction with academic staff and lead to a tendency to highlight the importance of relationship building with their academic colleagues. It also leads to a degree of wariness and, in some cases, feelings of inadequacy, on the part of the administrative staff member.

Findings of this study suggest that although administrative staff believe that they play a vital role in the teaching and learning processes of the University, they think that their customers have a relatively low opinion of the importance of their service. In the case of academic staff, the respondents feel that they are 'looked down' upon and their value to the organisation goes unrecognised. In the case of the students, administrative staff believe that they are generally unconsidered in the education process and if they are remembered at all, it will be by a minority of students and in negative terms. This is an issue that must be addressed by senior management, if their staff are to believe that their benefit to the organisation is fully appreciated.

Another finding from this research is that any attempt to improve customer service, in the administrative functions of higher education, must be approached with a degree of caution in respect to what already exists. Attempting to incorporate new management techniques, with the aim of improving service provision, could potentially undo a lot of hard work. Any attempts, within university administration, to improve the level of service being provided to internal and external customers must take into account the unique relationships that exists between administrative staff, academic staff and students. There is a danger that a formula-based, or generic approach, to interpersonal skills training and quality service provision, will do harm as well as good. For example, the belief, held by 
administrative staff members, that they are part of the educational process for the student and incorporate a mentor role in their work, does not sit well with many images of a service provider. This is an excellent attitude by the staff, however, and one that needs to be retained through any changes. This is because no amount of motivational training, by management, will be as effective to staff performance as a genuine belief, by individuals, that they make a positive difference to the student's educational development.

Likewise, the tendency for administrative staff to develop personal, rather than formal business relationships with academic staff, must be retained. Often the purpose of this is to overcome interpersonal communication problems (real or imagined), in order to facilitate quality service provision. Likewise, academic staff may resist attempts to formalise the customer-service provider relationship. Although a formalised approach offers a 'neutral' language, allowing the disparate cultures of administration and academia to find common ground, it also limits the potential for a genuine connection to be made between the two groups. The challenge for administrative management is to allow their staff to develop personal relationships with academic staff, while at the same time ensuring that quality service standards are not overlooked. It is recommended, however, that if the personal relationship allows for excellent service between the two parties, any 'textbook' mistakes in a professional approach to internal communication should be overlooked. Although this statement may seem axiomatic it is a fact that generic management systems can sometimes overlook the forest for the trees, due to a focus on processes and systems.

There is much to be said for a greater focus, within the higher education establishment, of students and inter-departmental colleagues as customers. This paper, however, argues that regardless of which management techniques are adopted, the unique relationships that exist between administrative staff and academic staff, and administrative staff and students must be retained. Generic management skills should be considered the first step towards quality service provision only, rather than an ultimate skill to be acquired.

Correspondence: Tim Pitman, Supervisor, Academic Registrar's Office, Curtin University of Technology, Perth, WA, Australia. Tel.: (08) 9266 3047; Fax: (08) 9266 4108; E-mail: pitman@vc.curtin.edu.au

\section{REFERENCES}

Allen, M. (1988) The Goals of Universities, Milton Keynes: Open University Press.

Anonymous, (1998) Academic and admin [sic] roles are not blurring, Campus Review, September, pp. 23-29. Anonymous, (1998) CEQ 'waste of time and resources' says GCG Study, Campus Review, October, pp. 14-20.

BanATA, T.W. \& KuH, D. K. (1998) A missing link in assessment: collaboration between academics and student affairs professionals, Change, pp. 40-46.

BEAN, J.P. \& BRADLEY, R.K. (1986) Untangling the satisfaction-performance relationship for college students, Fournal of Higher Education, 57(4), pp. 393-412.

Bladerston, F. E. (1995) Managing Today's University. San Francisco: Jossey-Bass Inc.

Brennan, L. \& Bennington, L. Working Paper Series, Monash University, Australia: Faculty of Business and Economics.

Brocato, R. \& Potocki, K. (1996) We Care About Students ... One Student at a Time, fournal for Quality and Participation, 19(1), pp. 74-79.

DAFt, R.L. (1991) Management, 2nd ed, Dryden Press.

Dervitsiotis, K.N. (1995) The objectives matrix as a facilitating framework for quality assessment and improvement in education, Total Quality Management, 6, pp. 563-570. 
Dixon, R. \& Domberger, S. (1995) The review of administration at The University of Sydney: a case study, Fournal of Tertiary Education Administration, 17(2), pp. 117-134.

Edmond, M. (1995) Quality support services for international students: AVCG code of ethical practice in the provision of education to overseas students, Foumal of Tertiary Education Administration, 17, pp. 51-62.

Li Ping Tang, T. \& Chamberlain, M. (1997) Attitudes toward research and learning: differences between administrators and faculty members, Journal of Higher Education, 6(2), pp. 212-255.

Marceau, J. (1996) Management of Higher Education Policy, in: S. Rees \& G. Rodley (Eds) The Human Costs of Managerialism: advocating the recovery of humanity. Leichhardt: Pluto Press.

Mersha, T. \& Adlakha, V. (1992) Attributes of service Quality: the consumers' perspective, International foumal of Service Industry Management, 3(3), pp. 34-45.

Miller, H. (1995) The Management of Change in Universities: universities, state and economy in Australia, Canada and the United Kingdom. Buckingham: Open University Press.

PIPER, D.W. (1993) Quality Education in Universities, Canberra: Australian Government Publishing Service.

Promnitz, J. \& Germain, C. (1996) Student Support Services and Academic Outcomes: achieving positive outcomes, Canberra: Australian Government Publishing Service.

REID, I. (1996) Higher Education or Education for Hire?: language and values in Australian universities. Brisbane: Queensland Central University Press.

REID I. (1998) Interview conducted with Professor I. Reid, 5 September 1998, Curtin University of Technology.

Shahalala, D. (1993) TQM applications in education, Executive Excellence, 10(5), pp. 6-7.

Sirvanci, M. (1996) Are students the true customers of higher education? Quality Progress, 29(10), pp. 99-102.

Weller, P. \& VArdon, S. (1997) Are prisoners clients? Australian foumal of Public Administration, 56(1), pp. 125-129. 